\title{
Management of Hepatitis C Antiviral Therapy Adverse Effects
}

\author{
Hubert Sung • Michael Chang • Sammy Saab
}

Published online: 24 December 2010

(C) The Author(s) 2010. This article is published with open access at Springerlink.com

\begin{abstract}
Hepatitis $\mathrm{C}$ is one of the leading causes of liver disease in the United States, affecting more than 4 million individuals. The current treatment regimen involves pegylated interferon in combination with ribavirin. Although antiviral treatment has been associated with a greater than $50 \%$ sustained viral response rate, the adverse effects have proven to be detrimental to quality of life and therapy adherence, and consequently lead to lower sustained viral response rates. This article identifies the most frequently described complications associated with pegylated interferon and ribavirin. The active management of these complications is discussed, including both preventive and empiric treatments.
\end{abstract}

Keywords Hepatitis C virus · Pegylated interferon ·

Ribavirin $\cdot$ Side effects $\cdot$ Management

\section{Introduction}

Hepatitis $\mathrm{C}$ is a major public health concern. With almost 4 million Americans with chronic infection, hepatitis $\mathrm{C}$ is the one of the leading causes of chronic liver disease and is the

H. Sung $\cdot$ S. Saab

Department of Surgery, University of California at Los Angeles, Los Angeles, CA, USA

M. Chang $\cdot$ S. Saab

Department of Medicine, University of California at Los Angeles, Los Angeles, CA, USA

S. Saab $(\bowtie)$

Pfleger Liver Institute, UCLA Medical Center,

200 Medical Plaza, Suite 214,

Los Angeles, CA 90095, USA

e-mail: SSaab@mednet.ucla.edu single most common indication for liver transplantation [13]. Antiviral therapy is effective in more than half of infected patients, but the actual rate of sustained viral response depends on viral, host, and adherence factors. Viral and host factors tend to be nonmodifiable, whereas interventions may increase adherence.

The current standard of care for hepatitis $C$ therapy is the combination of pegylated interferon and ribavirin [4]. Sustained viral response for antiviral therapy is about $55 \%$ $[5 \bullet, 6 \bullet]$. However, adverse effects from antiviral therapy directly affect treatment adherence and can decrease the likelihood of a sustained viral response. These complications can severely compromise quality of life [7]. Both interferon and ribavirin are associated with signature effects that are predictable, manageable, and improve with dose modification or discontinuation [8••]. Rarely is an adverse effect from hepatitis $\mathrm{C}$ antiviral therapy permanent. Adverse effects can arise from both interferon and ribavirin, and may lead to treatment termination and dose modifications in $10 \%$ to $15 \%$ and $32 \%$ to $42 \%$ of patients, respectively $[5 \bullet, 6 \bullet, 9]$. When interferon and ribavirin doses are reduced by a certain threshold, the sustained viral response may also decrease [10]. For instance, the results of a recent study by Reddy et al. [11••] demonstrated the sustained viral response is $34 \%$ when a patient's cumulative ribavirin dose decreases below $60 \%$.

An understanding of the antiviral adverse effects is essential to effectively deal with adverse effects in a timely manner. The goal during therapy is to maximize the likelihood of achieving a sustained viral response while improving tolerability and maintaining quality of life. Providers should discuss the potential issues with patients and with their social support. During clinic follow-up, patients should be queried about treatment adverse effects. Many times, the adverse effects can accumulate over time 
and lead to early treatment discontinuation. The current paper reviews the most frequent adverse effects associated with hepatitis $\mathrm{C}$ therapy, and proposes interventions to ameliorate complications. The adverse effects from pegylated interferon and ribavirin are considered separately.

\section{Pegylated Interferon}

The efficacy and therapeutic value of hepatitis $\mathrm{C}$ treatment is dependent on the degree of tolerability and adherence to the drugs, which in turn are related to the management of the side effects. The frequency and number of side effects related to interferon therapy are common, with most clinical trials reporting at least one interferon-related adverse effect in $95 \%$ of the patient group $[5 \cdot 10,12]$. The most frequently reported adverse effects from interferon include constitutional, hematologic, neuropsychiatric, and endocrinologic complications (Table 1). The onset of the adverse effects differ. The onset can be from minutes after the interferon injection, to months (Table 2).

\section{Constitutional Effects}

The most common adverse effects from interferon are constitutional symptoms. The severity of these side effects is inversely related to the amount of time after the interferon injection. Fatigue, headache, and fever were each reported in about $50 \%$ to $60 \%$ of treated patients $[6 \cdot, 9,12]$.

Constitutional effects can manifest early during therapy, even after the first dose of interferon [12]. However, several constitutional effects (e.g., fever) resolve or wane after the first several injections. Certain precautions can assist with the effects, such as maintaining adequate hydration and light to moderate exercise. The suggested intake of water in ounces is equivalent to half the patient's body weight in pounds. To prevent interferon therapy from interfering with work, injections should occur on Fridays. As a result, most of the constitutional effects will occur on Saturday. By Monday, treated patients tend to feel better. The use of acetaminophen or ibuprofen before the injection can also ameliorate many of the constitutional adverse effects. Other adverse effects (e.g., arthralgia) can respond to acetaminophen or ibuprofen. However, ibuprofen should be avoided in patients with liver cirrhosis.

\section{Hematologic Effects}

Hematologic side effects are the most recurrent abnormal laboratory values that can lead to dosage reductions and premature treatment termination [9]. Because of its myelosuppressive effect, interferon can affect hemoglobin, white blood cell, and platelet values. However, the anemia seen during combination treatment is mostly associated with ribavirin-induced hemolytic anemia.

The definition of neutropenia varies between the two commercially available pegylated interferons. For instance, neutropenia is defined as an absolute neutrophil count less than 500 cells $/ \mathrm{mm}^{3}$ when using pegylated interferon $\alpha-2 \mathrm{a}$, and below 750 cells $/ \mathrm{mm}^{3}$ when using pegylated interferon $\alpha-2 b[13,14]$. Certain populations appear to be more likely affected by the neutropenic effects of interferon, such as the

Table 1 Common adverse effects, frequency, and treatment of ribavirin plus interferon

\begin{tabular}{|c|c|c|c|c|}
\hline Adverse effect & Associated drug & Incidence & Management & References \\
\hline \multicolumn{5}{|l|}{ Constitutional } \\
\hline Fever & Interferon & $33 \%-56 \%$ & Acetaminophen or NSAIDs & {$[7,11 \bullet \bullet, 13,14]$} \\
\hline Fatigue/myalgias & Interferon & $48 \%-64 \%$ & Acetaminophen or NSAIDs & {$[7,11 \bullet \bullet, 13,14]$} \\
\hline Headache & Interferon & $52 \%-62 \%$ & Acetaminophen or NSAIDs & {$[7,11 \bullet \bullet, 13,14]$} \\
\hline Nausea & Ribavirin & $33 \%-43 \%$ & Antiemetics, hydration & {$[7,11 \bullet \bullet, 55]$} \\
\hline Arthralgias & Interferon & $25 \%-34 \%$ & Acetaminophen or NSAIDs & {$[7,11 \bullet \bullet, 13,14]$} \\
\hline \multicolumn{5}{|l|}{ Neuropsychiatric } \\
\hline Depression & Interferon & $29 \%-37 \%$ & SSRIs, close monitoring of symptoms & {$[7,11 \bullet \bullet, 13,14]$} \\
\hline \multicolumn{5}{|l|}{ Dermatological } \\
\hline Skin rash & Interferon & $22 \%-28 \%$ & Daily moisturizer use, topical corticosteroids & {$[7,9,13,14]$} \\
\hline \multicolumn{5}{|l|}{ Hematological } \\
\hline Neutropenia & Interferon & $8 \%-20 \%$ & Dose reduction or GCSF & {$[7,11 \bullet \bullet, 13,14]$} \\
\hline Anemia & Ribavirin & $9 \%-25 \%$ & $\begin{array}{l}\text { Dose reduction or discontinuation } \\
\text { Epogen analogues, blood transfusion }\end{array}$ & {$[7,9,55]$} \\
\hline Thrombocytopenia & Interferon & $<10 \%$ & Dose reduction or discontinuation & {$[7,11 \bullet \bullet, 13,14]$} \\
\hline
\end{tabular}

ANC absolute neutrophil count, GCSF granulocyte colony-stimulating factor, Hb hemoglobin, NSAIDS nonsteroidal anti-inflammatory, SSRI selective serotonin reuptake inhibitor 
Table 2 Time to onset of common adverse effects

\begin{tabular}{ll}
\hline Symptoms & Typical time of onset \\
\hline $\begin{array}{l}\text { Constitutional symptoms } \\
\text { Fever, myalgias, headache, arthralgias, nausea }\end{array}$ & Minutes to day \\
Neuropsychiatric symptoms & \\
Depression & 12 weeks to 6 months \\
Dermatological symptoms & \\
Rash & Minutes (localized, injection site) to weeks \\
Hematological symptoms & \\
Neutropenia & $2-6$ weeks \\
Anemia & 1 day to 4 weeks \\
Thrombocytopenia & $1-14$ days \\
\hline
\end{tabular}

elderly and non-African Americans [15]. Although African Americans are prone to constitutional neutropenia, initiation of interferon treatment usually only leads to minimal further decreases in neutrophil count. However, the clinical impact of neutropenia on significant infection is controversial. In a study of 119 subjects, 22 infections were documented and were dominated by sinusitis, pharyngitis, and urinary tract infections [15].

In most clinical trials, neutropenia is treated with dose modification. Interferon dose reduction occurs in about $17 \%$ to $20 \%$ of patients and treatment termination in $2 \%$ to $3 \%$ of patients $[16 \bullet \bullet, 17,18]$. The rapid decline in neutrophils usually occurs within the first 2 weeks of treatment initiation, with stabilization occurring over the next 4-6 weeks [9]. One study of 25 patients illustrated a median drop of $21 \%$ in neutrophils following the first dose of interferon [19].

Another option for patients who develop neutropenia from interferon therapy is the use of granulocyte colonystimulating factor (GCSF) [20-22]. Few clinical studies have included the use of GCSF $[20,21]$. These studies have indicated that the GCSF is able to raise neutrophil counts during interferon therapy. However, the results of a recent study failed to show a correlation between interferoninduced neutropenia and incidence or severity of infections [15]. Thus, although GCSF can improve neutrophil counts, future studies are required to determine the utility of GCSF in clinical practice, particularly given its increased costs and its own associated adverse effects. Regardless of the intervention of neutropenia, affected patients need regular cell counts to monitor neutrophil levels.

Another interferon-induced hematologic adverse effect is thrombocytopenia. Several mechanisms exist for the development of thrombocytopenia. It has been shown that platelet count can fall up to $50 \%$ because of posttranscriptional suppression of megakaryopoiesis or platelet sequestration in capillaries [23]. In addition, there have been rare cases of immune-mediated thrombocytopenia leading to significant decreases in platelet count, which can be rectified by termination of interferon treatment or corticosteroid therapy [24, 25]. Platelet reduction often occurs within the first $24 \mathrm{~h}$ of interferon administration, with nadir being reached within 8 weeks of therapy. Platelet levels will then stabilize at this low level during the length of therapy $[23,24]$. However, it may compound the already present thrombocytopenia associated with cirrhosis and portal hypertension. With pegylated interferon $\alpha-2 \mathrm{a}$, dose reduction is suggested when platelet counts fall below $50,000 / \mathrm{mL}$ and therapy termination when counts fall below $25,000 / \mathrm{mL}$ [13]. The threshold is set a little higher with respect to pegylated interferon $\alpha-2 b$, with limits of $80,000 / \mathrm{mL}$ for dose reduction and $50,000 / \mathrm{mL}$ for discontinuation [14]. Discontinuation of therapy is often followed by normalization of platelet counts within 4-8 weeks [23, 24]. Recent studies have shown eltrombopag, a thrombopoietin receptor agonist, to effectively increase platelet counts to greater than $250,000 / \mathrm{mm}^{3}$ in thrombocytopenic patients with hepatitis C virus [26]. However, its safety and utility in patients with advanced liver disease remains to be determined, because it may increase the risk of thrombosis [27].

\section{Neuropsychiatric Effects}

Not only is the prevalence of depression in patients with hepatitis $\mathrm{C}$ higher than the general population, antiviral therapy increases the likelihood of a variety of neuropsychiatric complications, including worsening depression, anxiety, and suicidal ideation [28]. Thus, it is imperative to assess for underlying depression and other preexisting psychiatric illness before considering antiviral therapy. In fact, antiviral therapy is contraindicated in patients with uncontrolled neuropsychiatric disorders. With a treated patient's approval, it is helpful for their social support to provide feedback on mood changes because patients themselves may not notice changes in their disposition.

About $20 \%$ to $30 \%$ of patients treated with interferons report depression during therapy or the exacerbation of a preexisting depressive state $[6 \bullet, 29]$. Depending on the type 
and severity of neuropsychiatric effects, patients may be monitored or may be treated with more frequent clinic visits or telephone calls, antidepressant medications, psychiatric referral, or dose modification or even discontinuation.

The selection of antidepressant medication requires tailoring, because depression may have nuances that improve or worsen with the choice of therapy [30]. The greatest experience with antidepressant medications is with selective serotonin reuptake inhibitors (SSRIs) [31, 32]. Although the use of antidepressant medication may not necessarily significantly improve the likelihood of a sustained viral response, it does improve adherence and help maintain quality of life [33]. In patients believed at increased risk of interferon-associated depression, preemptive treatment with SSRIs was associated with a significant reduction in the incidence of major depression [33].

\section{Endocrinologic Effects}

Thyroid abnormalities are the most commonly associated interferon-induced endocrinologic adverse effect, occurring in $1 \%$ to $6 \%$ of interferon-treated patients $[34,35]$. Both hypo- and hyperthyroidism can develop. Patients with hepatitis $\mathrm{C}$ may be predisposed to developing thyroid abnormalities because of an increased rate of thyroid autoantibodies prior to starting antiviral therapy [36]. For instance, one study described the development of thyroid disorder in $60 \%$ of patients with antithyroid microsome antibodies present prior to the initiation of interferon therapy, compared to only $3.3 \%$ of patients without these antibodies [35]. In a similar study, $38.5 \%$ of females with antithyroid peroxidase antibodies developed hypothyroidism versus only $7.8 \%$ of females lacking these antibodies [37].

Thyroid function tests should be obtained at baseline and every 12 weeks during antiviral treatment, and after treatment completion. If a patient develops symptomatic hypothyroidism, hormone replacement should be initiated while continuing antiviral therapy. Moreover, if the patient develops hyperthyroidism, the patient should be referred to an endocrinologist for further management with reevaluation of the antiviral regimen. Similar to the autoantibody destruction seen in the thyroid, antibodies to the adrenal cortex, pancreatic islet cells, and antiphospholipid antibodies have been reported with the use of interferon [38, 39]. Although rare, new-onset insulin-dependent diabetes mellitus with the presence of antibodies directed toward islet cells and insulin has been reported [40].

\section{Dermatologic Effects}

Many dermatologic adverse effects are associated with interferons, with an incidence ranging from $13 \%$ to $87 \%$
$[5 \bullet, 41]$. Besides nonspecific symptoms, reactions at the site of interferon injection are common, with $30 \%$ to $40 \%$ of patients complaining of erythema, pruritus, and tenderness $[6 \bullet, 42]$. Because the lesions may take weeks to resolve, it is recommended to rotate between unique injection sites. After injection, the sites are often warm and raised, expanding to a circumference of $5 \mathrm{~cm}$ or more. If the site continues to enlarge and remains warm and tender, the patient must be examined for possible abscess formation. Rarely, infection and skin necrosis are seen at the injection site. However, these symptoms do not necessarily warrant termination of treatment.

An additional major complaint from interferon therapy is skin dryness, which occurs in two of three treated patients [43]. Skin dryness can be exacerbated in cold weather, and may be accompanied by intense pruritus. Topical steroids, emollients, and soothing baths may help to alleviate these symptoms, but studies have not shown a significant response [43]. Another typical adverse effect seen with interferons is alopecia, occurring in about one third of patients, with a higher prevalence in females [44]. To combat alopecia, the patient can cut his/her hair short prior to interferon initiation and avoid pulling, braiding, or vigorously combing the hair. In addition, patients should avoid the use of harsh hair-care products, harsh hair dyes, hair dryers, and other products that may be detrimental to hair growth.

\section{Other Effects}

Neurologic, pulmonary, and ophthalmologic adverse effects associated with interferon use have been reported. Sensory and autonomic neuropathies, as well as Bell's palsy, have been documented with interferon use, most likely arising from an autoimmune phenomenon or neuronal injury caused by interferon stimulation of the immune system [45]. Neuropathy usually resolves with the termination of interferon treatment, but additional steroids and/or cyclophosphamide may be beneficial [12]. In addition to the neuropathies stated, there have been rare cases of myasthenia gravis. In such cases, interferon therapy is withdrawn and pyridostigmine therapy is initiated [46]. During interferon treatment, multiple pulmonary adverse effects can occur, such as interstitial pneumonitis, alveolar disease, and sarcoidosis reactivation. If a patient complains of continual cough and dyspnea on exertion or rest, a chest radiograph should be obtained to exclude pneumonitis. Possible bacterial pneumonia should be treated with proper antibiotics in conjunction with halting antiviral therapy, which can be reinitiated when there is clinical improvement. Occasionally, pulmonary function tests may be indicated, including forced vital capacity, forced expiratory volume, and carbon monoxide diffusion capacity, as well as a thoracic CT scan. Interferon-induced interstitial pneumonitis can be life- 
threatening, although it usually resolves with withdrawal of interferon. However, the most common cause for cough and shortness of breath is likely ribavirin-induced [43].

In addition to the pulmonary and neurologic effects, interferons have been associated with retinopathy (e.g., retinal hemorrhages and cotton wool spots), particularly in patients with diabetes [47]. In one study of 63 patients treated with antiviral therapy, $40 \%$ of patients developed retinal hemorrhages and 44\% developed cotton wool spots [48]. Diabetes and hypertension were risk factors for retinopathy [47, 49]. It is important for patients with pre-treatment risk factors for retinopathy to undergo retinal examination prior to treatment, and if any visual changes occur during treatment, to undergo ocular re-evaluation. Antiviral treatment must be halted if retinopathy worsens during therapy.

\section{Ribavirin}

Ribavirin is used with interferon to treat hepatitis C. Like interferon, it is associated with several adverse effects. Although the adverse effects from ribavirin appear to be less severe than those from interferon, maintaining ribavirin dose appears more critical to the likelihood of achieving a sustained viral response than sustaining the interferon dose [6•]. Thus, it is still imperative to understand and be able to manage ribavirin-associated complications.

\section{Hematologic Effects}

The signature adverse effect of ribavirin is anemia, occurring in up to $30 \%$ of treated individuals $[5 \bullet, 6 \bullet$. Ribavirin-related anemia is one the most common reasons for dosage reduction or discontinuation of the drug, resulting in $9 \%$ to $22 \%$ of patients requiring dosage reduction $[5 \cdot, 6 \bullet]$. Anemia can result in persistent fatigue, shortness of breath, and lower quality-of-life scores [12]. Treatment with ribavirin displays a drop in hemoglobin during the first 4 weeks of treatment, followed by stabilization, then normalization after treatment completion [9]. The mechanism of ribavirin-associated hemolytic anemia is unclear, but is believed to be related to impaired antioxidant defenses and red blood cell oxidative damages through its metabolites [51]. The degree of hemolytic anemia is directly related to ribavirin dose, renal function, and perhaps patient age [52, 53]. Recently, ITPA gene variants have been found to be protective of anemia in patients treated with ribavirin [54••].

The definition of anemia can vary. Although anemia may be suggested by the rate of hemoglobin drop, it is commonly defined by an absolute value of less than $10 \mathrm{~g} / \mathrm{dL}$ [55]. Intervention for ribavirin-induced anemia depends on the rate of hemoglobin decrease, absolute hemoglobin value, comorbidities, and symptoms. Therapeutic options include frequent monitoring, blood transfusion, erythropoietin grown factor, and ribavirin dose modification $[6 \bullet, 8 \bullet \bullet, 50 \bullet]$. The risk of significant anemia can be predicted by hemoglobin trends. For instance, a decrease in hemoglobin of at least of $1.5 \mathrm{~g} / \mathrm{dL}$ after 2 weeks predicts significant decreases after 4 weeks of therapy [56]. Recognition of impending anemia may prompt small reductions of ribavirin to avoid significant decline in hemoglobin.

There is a discrepancy between the intervention for anemia according to package inserts, and what is often done in clinical practice. The respective package inserts recommend decreasing the ribavirin dose by $200 \mathrm{mg} /$ day when using peginterferon $\alpha-2 \mathrm{~b} /$ ribavirin and by $600 \mathrm{mg} /$ day when using peginterferon $\alpha-2 \mathrm{a} /$ ribavirin, if hemoglobin decreases to less than $10 \mathrm{~g} / \mathrm{dL}$ in a patient without cardiac risk factors [13, 14, 55]. The package inserts also recommend termination of ribavirin if the hemoglobin levels decrease below $8.5 \mathrm{~g} / \mathrm{dL}$.

Studies have shown erythropoietin can improve hemoglobin values, maintain ribavirin dosage levels, and improve quality of life in patients with symptomatic ribavirin-induced anemia [57]. Despite improved adherence with erythropoietin, no studies have shown that the use of erythropoietin translates to higher sustained viral response. This may be due to the large cohort of treated patients needed to show a beneficial effect. There have been reported cases of antibody-mediated pure red-cell aplasia induced by erythropoietin, which is potentially life-threatening, but resolves with termination of erythropoietin treatment and initiation of danazol [58]. A recent study highlighted the correlation between the magnitude of hemoglobin decline and the likelihood of sustained viral response, and indicated an association between the magnitude of hemoglobin decline and ribavirin exposure [59]. Erythropoietin use in early-onset anemia minimized treatment discontinuation and led to higher sustained viral response rates. However, erythropoietin for anemia after 8 weeks of therapy was not associated with higher sustained viral response rates. Moreover, erythropoietin has been linked to a greater incidence of mortality with its use in ischemic stroke patients [60]. These recent concerns regarding raised risks of thromboembolic events and aplastic anemia with erythropoietin justify the judicious use of this agent.

\section{Other Effects}

Other ribavirin-associated complications include nausea and pulmonary, dermatologic, and teratogenic effects. Studies have shown that $25 \%$ to $40 \%$ of patients complain of nausea $[5 \cdot, 6 \bullet, 12]$. However, this symptom can be managed with alterations in the patient's dietary regimen. More specifically, along with maintaining adequate hydration, patients should avoid acidic, spicy, sweet, or greasy foods. Instead, dietary intake should consist of clear beverages and dry foods (e.g., 
toast and crackers). If nausea persists after dietary changes, antiemetics may be prescribed.

Ribavirin therapy is often associated with a dry, nonproductive cough, which resolves only upon termination of treatment. Most patients can tolerate this adverse effect, and thus it is not a major cause of dose reductions or treatment termination. However, if the cough becomes productive or other clinical indications are present, a chest radiograph should be considered.

The addition of ribavirin in combination therapy increases the incidence of dermatologic adverse effects. More specifically, one study compared the incidence of skin rash in two groups, one receiving interferon monotherapy and one receiving interferon and ribavirin. Monotherapy resulted in an $8 \%$ incidence, whereas combination therapy resulted in $28 \%$ incidence [41]. Dermatologic side effects with combination therapy are typified by generalized pruritus, skin xerosis, and eczematiform lesions, which are localized to the extremities. Although ribavirin is shown to increase the incidence of dermatologic conditions when added to interferon treatment, it should be noted that ribavirin alone may cause rash and pruritus. Ribavirin must be discontinued if an acute hypersensitivity reaction develops. However, transient rashes do not require ribavirin treatment interruption [55]. Management entails topical corticosteroids, which may be tapered once signs of inflammation and irritation begin to recede. Preventive measures can be taken, with daily emollient therapy and skin moisturizers to commonly affected areas.

Ribavirin has been associated with significant teratogenic or embryocidal effects in nonhuman animal species exposed to it; therefore, patients must take proper precautions when beginning ribavirin treatment. Moreover, ribavirin therapy, which according to the Food and Drug Administration is pregnancy category $\mathrm{X}$, is contraindicated in pregnant woman and in the male partners of women who are pregnant. It is imperative for patients to avoid pregnancy during ribavirin treatment and for 6 months after treatment completion. It is suggested that two reliable forms of effective contraception be used during this time. Upon cessation of treatment, recovery from ribavirin-induced testicular toxicity was apparent within one or two spermatogenesis cycles. Although human studies are lacking, there is a ribavirin pregnancy registry that enrolls pregnant women who have been directly or indirectly exposed to ribavirin [61]. Although underpowered, the results of a recent registry questioned the association between ribavirin and human teratogenicity [62].

\section{Conclusions}

The current standard of care for the treatment of hepatitis C infection involves the use of pegylated interferon and ribavirin. This antiviral combination therapy is associated with several potentially serious adverse effects. Fortunately, pegylated interferon and ribavirin have been available for almost a decade, and most of the adverse effects regarding incidence and time of onset have been defined. The management of these antiviral complications has also been well described, including preventive and empiric strategies. Understanding the limitations of current treatment is essential to assure quality of life and adherence during therapy, and may provide insight to deal with the finer points of future treatment strategies.

Disclosure Conflicts of interest: H. Sung-none; M. Chang-none; S. Saab - consultancy, grants, speakers' honoraria, and travel reimbursement from Bristol-Myers Squibb, Gilead, Three Rivers, Genentech, Merck, Bayer, and Onyx, and stock/stock options in Gilead, Vertex, and Zymogenetics.

Open Access This article is distributed under the terms of the Creative Commons Attribution Noncommercial License which permits any noncommercial use, distribution, and reproduction in any medium, provided the original author(s) and source are credited.

\section{References}

Papers of particular interest, published recently, have been highlighted as:

- Of importance

•. Of major importance

1. National Digestive Disease Information Clearinghouse (NDDIC) Chronic Hepatitis C: Current Disease Management. Available at http://digestive.niddk.nih.gov/ddiseases/pubs/chronichepc/chron ichepc.pdf. Accessed August 2010.

2. Lavanchy D: Chronic viral hepatitis as a public health issue in the world. Best Pract Res Clin Gastroenterol. 2008;22(6):991-1008.

3. Armstrong GL, Wasley A, Simard EP: The Prevalence of Hepatitis C Virus Infection in the United States, 1992-2002. Ann Intern Med 2006;144:705-14.

4. Ghany MG, Strader DB, Thomas DL, et al.: Diagnosis, management, and treatment of hepatitis C: an update. Hepatology 2009 Apr;49(4):1335-74.

5. - Fried MW, Shiffman ML, Reddy KR, et al.: Peginterferon alfa2a plus ribavirin for chronic hepatitis $\mathrm{C}$ virus infection. $\mathrm{N}$ Engl $\mathrm{J}$ Med 2002 Sep; 347:975-82. Registration trial that established peg-interferon and ribavirin as standard of care for the treatment of hepatitis $C$ virus infection. Trial studied the efficacy and safety of combination treatment.

6. - Manns MP, McHutchinson JG, Gordon SC, et al.: Peginterferon alfa-2b plus ribavirin compared with interferon alfa- $2 b$ plus ribavirin for initial treatment of chronic hepatitis $\mathrm{C}$ : a randomised trial. Lancet 2001;358:958-965. Registration trial that established peg-interferon and ribavirin as standard of care for the treatment of hepatitis $C$ virus infection. Trial studied the efficacy and safety of combination treatment.

7. Foster GR: Quality of life considerations for patients with chronic hepatitis C. J Viral Hepat. 2009 Sep;16(9):605-11. 
8. - Chak E, Saab S: Pegylated Interferon and Ribavirin Dosing Strategies to Enhance Sustained Virologic Response. Curr Hepat Rep 2010 Aug;9(3):147-154. This article describes how dose modification or discontinuation can affect sustained viral response, and how dose and duration are dependent on the patient.

9. Fried MW: Side effects of therapy of hepatitis $\mathrm{C}$ and their management. Hepatology 2002 Nov;36(5 Suppl 1):S237-44.

10. McHutchinson JG, Manns M, Patel K, et al.: Adherence to combination therapy enhances sustained response in genotype-1infected patients with chronic hepatitis C. Gastroenterology 2002;123:1061-9.

11. •• Reddy KR, Nelson DR, Zeusem S: Ribavirin: current role in the optimal clinical management of chronic hepatitis C. J Hepatol 2009 Feb;50(2):402-11. This article identifies the importance of maintaining adequate cumulative ribavirin levels within the hepatitis $C$ patient and its effect on sustained viral response.

12. Russo MW, Fried MW: Side effects of therapy for chronic hepatitis C. Gastroenterology 2003;124:1711-9.

13. Pegasys [package insert]. Nutley, NJ: Hoffman-La Roche Inc. 2008.

14. PegIntron [package inset]. Kenilworth, NJ: Schering-Plough Corp. 2009.

15. Soza A, Everhart JE, Ghany MG, et al.: Neutropenia during combination therapy of interferon alfa and ribavirin for chronic hepatitis C. Hepatology 2002;36:1273-1279.

16. •- Antonini MG, Babudieri S, Maida I, et al.: Incidence of neutropenia and infections during combination treatment of chronic hepatitis $\mathrm{C}$ with pegylated interferon alfa- $2 \mathrm{a}$ or alfa- $2 \mathrm{~b}$ plus ribavirin. Infection 2008 Jun;36(3):250-5 Epub 2008 May 3. This trial examined the incidence of pegylated interferon-induced neutropenia and its correlation with infection. It suggests that interferon-induced neutropenia is not associated with an increased risk of infection and that current guidelines for dose reduction may be too strict.

17. Hadziyannis SJ, Sette H, Morgan TR, et al.: Peginterferon-alfa 2a and ribavirin combination therapy in chronic hepatitis C. Ann Intern Med 2004;140:346-355.

18. Pockros PJ, Carithers R, Desmond P, et al.: Efficacy and safety of a 2-dose regimens of peg interferon alfa-2a compared with interferon alfa-2a in chronic hepatitis $\mathrm{C}$ : a multicenter randomized controlled trial. Am J Gastroenterol 2004;99:1298-305.

19. Peck-Radosavljevic M, Wichlas M, Homoncik-Kraml M, et al.: Rapid suppression of hematopoiesis by standard or pegylated inteferon-alpha. Gastroenterology 2002;123:141-151.

20. Fukuda A, Kobayashi H, Teramura K, et al.: Effects of interferonalpha on peripheral neutrophil counts and serum granulocyte colony-stimulating factor levels in chronic hepatitis $\mathrm{C}$ patients. Cytokines Cell Mol Ther 2000;6:149-154.

21. Carreno V, Martin J, Pardo M, et al.: Randomized controlled trial of recombinant human granulocyte-macrophage colony-stimulating factor alone or in combination with interferon-alpha- $2 \mathrm{~b}$ for treatment of chronic hepatitis C. J Hepatol 1998; 28:382-389.

22. Sharvadze L, Karchava M, Bolokadze N, et al.: Safety and efficacy of systematic administration of Filgrastim to prevent neutropenia and infections with hepatitis C. Georgian Med News. 2009 Oct;(175):32-5.

23. Yamane A, Nakamura T, Suzuki H, et al.: Interferon-alpha- 2binduced thrombocytopenia is caused by inhibition of platelet production but not proliferation and endomitosis in human megakaryocytes. Blood 2008;112:542-50.

24. Pockros PJ, Duchini A, McMillan R, et al.: Immune thrombocytopenic purpura in patients with chronic hepatitis $\mathrm{C}$ virus infection. Am J Gastroenterol 2002;97:2040-2045.

25. Dourakis SP, Deutsch M, Hadziyannis SJ: Immune thrombocytopenia and alph-interferon therapy. J Hepatol 1996;25:972-5.

26. McHutchinson JG, Dusheiko G, Shiffman ML, et al.: Eltrombopag for thrombocytopenia in patients with cirrhosis associated with hepatitis C. N Engl J Med 2007;357:2227-36.
27. Danish FA, Koul SS, Subhani FR, et al.: Considerations in the management of hepatitis $\mathrm{C}$ virus-related thrombocytopenia with eltrombopag. Saudi J Gastroenterol. 2010 Jan-Mar;16(1):51-6.

28. Al-Huthail YR: Neuropsychiatric side-effects of interferon alfa therapy for hepatitis $\mathrm{C}$ and their management: a review. Saudi J Gastroenterol. 2006 Apr-Jun;12(2):59-67.

29. Dieperink E, Ho SB, Tetrick L, et al.: Suicidal ideation during interferon-alpha $2 \mathrm{~b}$ and ribavirin treatment of patient with chronic hepatitis C. Gen Hosp Psychiatry 2004;26:237-40.

30. Sockalingam S, Abbey SE. Managing depression during hepatitis C treatment. Can J Psychiatry. 2009 Sep;54(9):614-25.

31. Kraus MR, Schafer A, Schottker K, et al.: Therapy of interferoninduced depression in chronic hepatitis $\mathrm{C}$ with citalopram: a randomised, double-blind placebo-controlled study. Gut 2008;57:531-6.

32. Hauser P, Khosla J, Aurora H, et al.: A prospective study of the incidence and open-label treatment of interferon-induced major depressive disorder in patients with hepatitis C. Mol Psychiatry 2002;7:942-947.

33. Schaefer M, Schwaiger M, Garkisch AS, et al.: Prevention of interferon-alpha associated depression in psychiatric risk patients with chronic hepatitis C. J Hepatol 2005;42:793-798.

34. Tomer Y: Hepatitis $\mathrm{C}$ and interferon induced thyroiditis. $\mathrm{J}$ Autoimmun. 2010 May;34(3):J322-6.

35. Marazuela M, Garca-Buey L, Gonzalez-Fernandez B, et al.: Thyroid autoimmune disorders in patients with chronic hepatitis $\mathrm{C}$ before and during interferon-alpha therapy. Clin Endocinol 1996;44:635-42.

36. Doi F, Kakizaki S, Takagi H, et al.: Long-term outcome of interferon-alpha induced autoimmune thyroid disorders in chronic hepatitis C. Liver Int 2006 Apr;25(2):242-6.

37. Watanabe U, Hashimoto E, Hisamitsu T, et al.: The risk factor for development of thyroid disease during interderon-alpha therapy for chonic hepatitis C. Am J. Gastrolenterol 1994;89:399-403.

38. Wesche B, Jaeckel E, Trautwein C, et al.: Induction of autoantibodies to the adrenal cortex and pancreatic islet cells by interferon alpha therapy for chronic hepatitis C. Gut 2001;48:378-383.

39. Betterle C, Fabris P, Zanchetta R, et al.: Autoimmunity against pancreatic islets and other tissues before and after interferon-alpha therapy in patients with hepatitis $\mathrm{C}$ virus chronic infection. Diabetes Care 2000;23:1177-1181.

40. Fabris P, Betterle C, Greggio NA, et al.: Insulin-dependent diabetes mellitus during alpha-interferon therapy for chronic viral hepatitis. J Hepatol 1998;28:514-517.

41. McHutchinson JG, Gordon SC, Schiff ER, et al.: Interferon alfa$2 \mathrm{~b}$ alone or in combination with ribavirin as initial treatment for chronic hepatitis C. Hepatitis Interventional Therapy Group. N Engl J Med 1998;339:1485-92.

42. Lubbe J, Kerl K, Negro F, et al.: Clinical and immunological features of hepatitis $\mathrm{C}$ treatment-associated dermatitis in 36 prospective cases. Br J Dermatol 2005;153:1088-90.

43. Aspinall RJ, Pockros PJ.: Review article: the management of sideeffects during therapy for hepatitis C. Aliment Pharmacol Ther 2004;20:917-929.

44. Lang AM, Norland AM, Schuneman RL: Localized interferon alfa-2b-induced alopecia. Arch Dermatol 1999;135:1126-8.

45. Stubgen JP: Interferon alpha and neuromuscular disorders. K Neuroimmunol 2009;207:3-17.

46. Weegink CJ, Chamuleau RA, Reesink HW, et al.: Development of myasthenia gravis during treatment of chronic hepatitis $\mathrm{C}$ with interferon-alpha and ribavirin. J Gastroenterol 2001;36:723-4.

47. Jain K, Lam WC, Waheeb S, et al.: Retinopathy in chronic hepatitis $\mathrm{C}$ patients during interferon treatment with ribavirin. $\mathrm{Br} \mathrm{J}$ Ophthalmol 2001;85:1171-1173. 
48. Kawano T, Shigehira M, Uto H, et al.: Retinal complications during interferon therapy for chronic hepatitis C. Am J Gastroenterol 1996;91:309-313.

49. Hayasaka S, Fujii M, Yamamoto Y, et al.: Retinopathy and subconjunctival haemorrhage in patients with chronic viral hepatitis receiving interferon alfa. Br J Ophthalmol 1995;79:150-152.

50. •• McHutchison JG, Manns MP, Brown RS Jr, et al.: Strategies for managing anemia in hepatitis $\mathrm{C}$ patients undergoing antiviral therapy. Am J Gastroenterol. 2007 Apr;102(4):880-9. This clinical review outlines the importance of anemia management and its effects on sustained viral response. The study reviews the benefits and disadvantages of erythropoietin use to combat ribavirin-induced anemia.

51. DeFranceschi L, Fattovich G, Turrini F, et al.: Hemolytic anemia induced by ribavirin therapy in patients with chronic hepatitic $\mathrm{C}$ virus infection: role of membrane oxidative damage. Hepatology 2000;31:997-1004.

52. Saab S, Oh MK, Ibrahim AB, et al.: Anemia in liver transplant recipients undergoing antiviral treatment for recurrent hepatitis $\mathrm{C}$. Liver Transpl. 2007;13(7):1032-8.

53. Nomura H, Tanimoto H, Kajiwara E, et al.: Factors contributing to ribavirin-induced anemia. J Gastroenterol Hepatol. 2004;19:13127.

54. • Fellay J, Thompson AJ, Ge D, et al.: ITPA gene variants protect against anaemia in patients treated for chronic hepatitis C. Nature. 2010;464:405-8. This recent study suggests that genetic variants leading to inosine triphosphate deficiency protect against ribavirin-induced hemolytic anemia in hepatitis $C$ patients.

55. Ribavirin [package insert]. South San Francisco, CA: Hoffman-La Roche Inc. 2010.

56. Reau N, Hadziyannis SJ, Messinger D, et al: Early predictors of anemia in patients with hepatitis $\mathrm{C}$ genotype 1 treated with peginterferon alfa-2a (40KD) plus ribavirin. Am J Gastroenterol. 2008 Aug;103(8);1981-8.

57. Dieterich DT, Prockros P, Schiff ER, et al.: Interim results of a randomized, double-blind placebo-controlled study demonstrates that epoietin-alfa (PROCRIT) allows maintenance of ribavirin dosing. Hepatology 2002;493.

58. Stravitz RT, Chung H, Sterling RK, et al.: Antibody-mediated pure red cell aplasia due to epoetin alfa during antiviral therapy of chronic hepatitis C. Am J Gastroenterol. 2005;100:1415-9.

59. Sulkwski MS, Shiffman ML, Afdhal NH, et al.: Hepatitis C virus treatment-related anemia is associated with higher sustained virologic response rate. Gastroenterology. 2010;139(5):1602-11.

60. Jia L, Chopp M, Zhang L, et al.: Erythropoietin in combination of tissue plasminogenactivator exacerbates brain hemorrhage when treatment is initiated $6 \mathrm{~h}$ after stroke. Stroke 2010 Sep;41(9):2071-6.

61. Ribavirin Pregnancy Registry. Available at http://ribavirinpregnan cyregistry.com/. Accessed September 2010.

62. Roberts SS, Miller RK, Jones JK, et al.: The Ribavirin Pregnancy Registry: Findings after 5 years of enrollment, 2003-2009. Birth Defects Res A Clin Mol Teratol. 2010;88:551-9. 